\title{
Engineering, Project and Production Management: Optimizing Performance in Risky Economic Environments
}

\author{
Joanicjusz Nazarko \\ Editor \\ Editorial \\ Available online April 15, 2013
}

The current edition of the Journal is rather broad in the scope of topics covered and consists of five papers. Three papers contribute to the understanding of performance issues related to production in general and to engineeringbased projects in particular. One paper focuses on financial risk related to project cost uncertainties, and one to policy instruments surrounding the recurring problem of carbon gas emissions to the atmosphere.

The paper by M. Salloum of Volvo Construction Equipment analyzes two case studies performed between 2008 and 2011 explaining on the basis of 28 interviews in two firms the ongoing changes in performance measures in the industry. The reasons for the evolution of these measures have been explained, chief among them the need for continuous improvement in a constantly competitive production environment, rather than the changes occurring in internal or external technical or business conditions.

S. Al-Otaibi et al. of Saudi Ministry of Interior and Loughborough University (UK) describe potential of the 'lessons learned' from the adoption of a new Standard Design Model used in the development of the Ministry's construction program to manage its project portfolio and enhance project performance. Typical design projects were reviewed based on eight case studies and interviews with 24 stakeholders involved in the implementation of the model. Fourteen critical success factors were identified and classified into three categories: adaptability to the context, contract management, and construction management. It is hoped that the proposed model will have a significant effect on the improvement of design and construction project performance in the Ministry's portfolio.

S.O. Ojo and I.J. Ikpo from Obafemi Awolowo University (Nigeria) describe a new way of determining performance of procurement methods against contractor/supplier selection criteria. The authors aim at achieving an incremental improvement with the use of Multi-Attribute Utility Approach to the selection of the most appropriate project procurement option. This is accomplished by the use of the outranking-satisfying technique to determine the correctness of the results derived from the averaging method used in conjunction with the utility factors implemented within MAUA. The outcome described in the paper indicates significant progress with the quality of the selection results related to the identification of the most advantageous project procurement approach.

J.I. Teye-Buertey et al. from two academic and one consulting organization in Ghana research financial impacts of various risk factors related to construction project cost contingencies through the use of the evidential reasoning method. They present a qualitative tool, Failure Mode Effect Analysis, and a quantitative tool, Evidential Reasoning Method, both relying on empirical judgment. They employ a structured questionnaire to reveal that four work sections are prone to significant changes in scope of the contracted work, and these sections are associated with seven distinct risk factors. Based on their analysis, the authors conclude that the customary contingency rate of $10 \%$ does not reflect actual contingency amounts attributed to typical large construction projects in Ghana, as these normally range from above $13 \%$ to almost $18 \%$ in some cases. Practical implications for the cost estimation practices should be drawn based on these findings.

S. Suanmali and B. Limmeechokchai from Thammasat University (Thailand) provide an assessment of the government policy related to biofuel utilization on carbon dioxide emissions particularly from the transportation sector of the national economy. The methodology used in the presented research is based on energy input-output analysis in terms of greenhouse gas/carbon dioxide emissions. Conversion factors established in 2007 were used in the current research, with major revisions expected in 2015 after the policy in question has been fully implemented.

On behalf of all editors of the Journal, let me wish our esteemed readers continuous intellectual stimulation and constructive reflections following the reading of the articles in this issue. It is our hope that the contents of the presented papers will lead to practical implementation of the research ideas and methods presented here. 